\title{
The Use of Digital Fabrication as a Support to the Production of a Spatial Orientation Model at Santa Catarina Federal University
}

\author{
Regiane Pupo ${ }^{1}$, Vanessa Casarin ${ }^{1}$, Gabriel Querne $^{1}$, Larissa Adriano ${ }^{1}$, \\ Mariana Pfleger ${ }^{1}$, Venancio Perin ${ }^{1}$ \\ ${ }^{1}$ Universidade Federal de Santa Catarina, Brasil \\ regipupo@gmail.com \\ vanessa.arq@gmail.com \\ quernegabriel@gmail.com \\ larissakadriano@gmail.com \\ marianabsp96@gmail.com \\ venanperin@gmail.com
}

\begin{abstract}
The aim of this research project is to build and evaluate a model supported by digital technologies to help spatial orientation in the Federal University of Santa Catarina campus. The process explored a people-centered solution, based on Design Thinking, to answer the outlined research question regarding if a scale model supported by digital tools could help users in their wayfinding process in the campus. The methodology is defined as a non-linear process that analyzes user's needs. Through its three main phases: immersion (problems identification), ideation (solution findings) and prototyping (desired solution materialization) the research explores digital fabrication tools as a design support. At the same time, results showed that a model supported by digital technologies and other tools such as QR Code solutions to point directions would help campus users to easily find their destination during wayfinding process.
\end{abstract}

Keywords: Spatial orientation, Wayfinding, Digital Fabrication, 3D printing, University campus.

\section{Introdução}

O campus Reitor João David Ferreira Lima, sede da Universidade Federal de Santa Catarina (UFSC), está localizado em Florianópolis, no estado de Santa Catarina, Brasil, e é atualmente setorizado em onze centros de ensino com 
uma comunidade acadêmica de, pelo menos, setenta mil pessoas, em uma área de aproximadamente 450 mil metros quadrados. Posicionado no centro urbano entre os bairros Trindade, Carvoeira, Pantanal e Córrego Grande, existe uma dificuldade muito grande de usuários - estudantes, professores, funcionários e visitantes, em passagem pela área, na locomoção e orientação para determinados locais do campus. O atual método de orientação espacial ali implantado revela falta de informações, sinalização precária e danificada, bem como sua subutilização para determinados centros.

Segundo Passini (1984), a desorientação é uma questão que sempre preocupou a humanidade no passado e, com o desenvolvimento do ambiente construído, foi intensificada e ganhou mais complexidade, o que pode provocar frustração, estresse e outras consequências desastrosas. Cada indivíduo traduz à sua maneira o que é percebido no espaço e gera novos sentidos e interpretações a partir de um conhecimento vivido mediante experiências subjetivas e intersubjetivas (Toselo et. al, 2015). Passini (1984 apud CASARIN, 2012, p.52) define a orientação espacial quando:

Pode ser entendida como um conjunto de processos naturais e cognitivos capazes de organizar as partes percebidas do ambiente em um conjunto de mapas, respeitando certas propriedades geométricas. Pode ainda ser descrita como a habilidade de uma pessoa de determinar sua posição numa representação do ambiente feita por mapas cognitivos. (PASSINI, 1984 apud CASARIN, 2012, p.52)

Compreender as demandas por orientação espacial no campus promoverá as bases necessárias para definir um instrumento que possa auxiliar na orientação do usuário em qualquer que seja sua direção no ambiente universitário. O vasto uso de ferramentas digitais tais como técnicas de fabricação digital, por exemplo, tem sido aplicado em diversos campos de atuação e poderiam ser empregadas para colaborativamente auxiliar usuários a se locomover no campus com facilidade e decisões assertivas.

Desta forma, a presente pesquisa buscou uma ferramenta que pudesse ser instalada em um ponto estratégico de chegada ao campus, com o objetivo de fortalecer a estrutura logística da universidade e, ainda, facilitar sua vivência no âmbito universitário.

O resultado da pesquisa é uma maquete em escala $1 / 750$ de todo o campus, produzida por ferramentas de fabricação digital, para ser utilizada como estratégia de wayfinding e estrutura funcional que concentra informações e indica direções, transformando processos de orientação mais acessíveis para os usuários (GIBSON, 2009). Além de propor um modelo de todo o campus universitário, este trabalho visa fornecer um melhor entendimento do espaço sendo estudado, aprimorando a percepção da comunidade universitária para com o meio em que vive. 


\section{$2 \quad$ Materiais e métodos}

A metodologia de trabalho utilizada baseia-se no Design Thinking, processo não-linear que permite analisar as necessidades do usuário aliado a sistemas de inovação e composta por três passos que podem se sobrepor - imersão, ideação e prototipação (BROWN, 2010). O Design Thinking refere-se a uma abordagem direcionada ao ser humano, em que o produto ou serviço planejado deve adaptar-se ao usuário, e não o sentido oposto. Brown (2010) considera a existência de "pontos de partida" e de referência que podem ajudar no desenvolvimento do projeto, como um sistema de fases projetuais que podem, ou não, se sobrepor, de forma não-linear.

\subsection{Processo de Imersão}

Segundo Vianna et al (2012), a imersão pode ser dividida em dois períodos, denominados imersão preliminar e imersão em profundidade, em que acontece o primeiro contato com o assunto e o usuário. Na fase de imersão preliminar da presente pesquisa, com o intuito de embasar e sustentar a aplicação dos objetivos finais de intervenção, as atividades se concentraram em uma revisão sistemática, bibliográfica e de referências visuais sobre o tema. Assim, foi possível proporcionar um entendimento inicial sobre seus dois eixos norteadores: orientação espacial e fabricação digital.

A revisão sistemática teve como objetivo situar a pesquisa inicialmente em palavras-chave, para encontrar bases de realizações similares às que se almeja no caso aqui estudado. Em princípio, foram selecionadas seis palavraschave para busca no portal "CumInCAD", portal que reúne publicações de diversos congressos de Arquitetura e Design do mundo. As palavras-chave foram utilizadas em inglês: Spatial Orientation (Orientação Espacial); Rapid Prototyping (Prototipagem Rápida); Digital Fabrication (Fabricação Digital); Tactile Model (Maquete Tátil); Urban Model (Maquete Urbana); e University campus (Campus Universitário) com as quais foi possível encontrar 600 trabalhos. Após análise e revisão de conteúdo de todos, 73 artigos, de fato, colaboraram com a construção desta pesquisa.

Para fortalecer o processo projetual, buscou-se outros exemplos de materialização do espaço que contribuíssem para a localização e orientação espacial em locais públicos. Percebeu-se, durante esse processo, a existência de uma preocupação em relação à orientação de deficientes visuais, por meio da criação de mapas e maquetes táteis que os permitem ter um melhor entendimento do espaço em que ocupam e caminhos a serem seguidos. Entretanto, pouco se encontrou em relação a maquetes com uso voltado diretamente à orientação espacial. $\mathrm{O}$ uso de mapas em 2D ainda tem predominância, apesar de muitas vezes seu entendimento ser dificultado pelo excesso de informação e expressões gráficas dificultosas. Por isso, com a crescente adesão dos processos de impressão 3D e prototipagem digital pelo mercado e seu consequente custo reduzido e acesso facilitado, há uma 


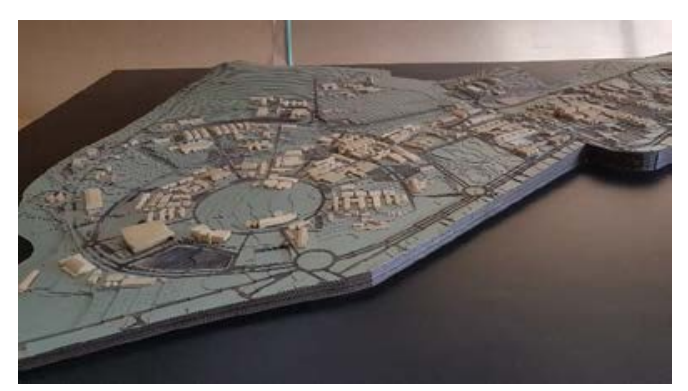

Figura 3: Maquete Campus UNICAMP. Fonte: Acervo pessoal, 2009

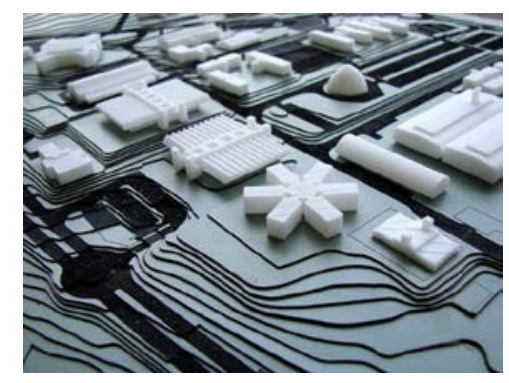

Figura 4: Detalhe maquete Campus UNICAMP. Fonte: Acervo pessoal, 2009

Na imersão em profundidade, a fim de se obter um estudo mais acurado do local a ser estudado, procurou-se compreender as dificuldades de orientação espacial no campus, analisar os fluxos existentes, as conexões entre os centros, desenvolvendo-se, assim, estudos de campo em diferentes locais e horários. As análises foram feitas por meio de observação, levantamento das edificações e acessos ao campus, questionário com usuários e diálogos com as pessoas que utilizam o campus, de diferentes cursos, idades e interesses.

O resultado destacou a forte identidade e potencial referencial da Praça da Cidadania e seu entorno, principalmente a Biblioteca Universitária (BU). O questionário apontou que os pontos dessa centralidade foram citados 173 vezes como referência de orientação dentro do campus, dos quais 65 referemse à Biblioteca Universitária (BU) e 56 ao Centro de Eventos e 52 à Reitoria, todos adjacentes à praça. Corroborando a este resultado, de acordo com Soares et al (2017), a praça da Cidadania é o local mais integrado e visível e, ainda, localizado próximo ao principal ponto de ônibus central da UFSC.

\subsection{Processo de Ideação}

A segunda fase da metodologia de Design Thinking, segundo Vianna (2012), o processo de ideação, tem o objetivo de síntese e desenvolvimento de soluções para os pontos críticos levantados na etapa anterior. Após a realização de estudos de observação, levantamento das edificações e acessos ao campus, questionário e diálogos com os usuários, pôde-se observar os pontos de convergência de fluxos e a demanda por sinalização que apoia a orientação no campus. A avaliação dos resultados auxiliou no levantamento das problemáticas e dos potenciais do local de estudo, resultando na possível confirmação da relevância da diretriz proposta em que a maquete de orientação do campus poderia ser localizada na Praça da Cidadania, ponto central do campus e conhecido por todos.

Contando com o apoio do projeto Rotas Acessíveis do Departamento de Projetos de Arquitetura e Engenharia da UFSC (DPAE), foram necessários estudos sobre a setorização existente, pontos de acesso, rotas, ruas e 


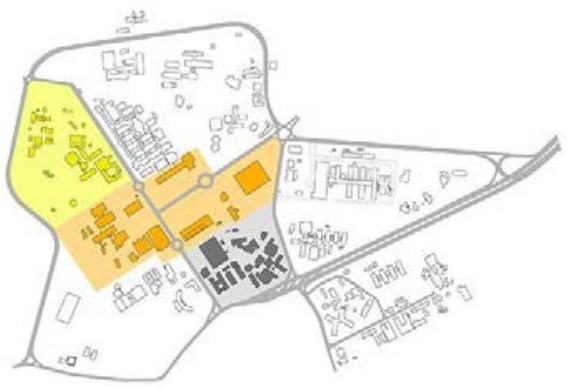

Figura 10: Identificação dos 3 setores para teste. Fonte: Autores, 2019

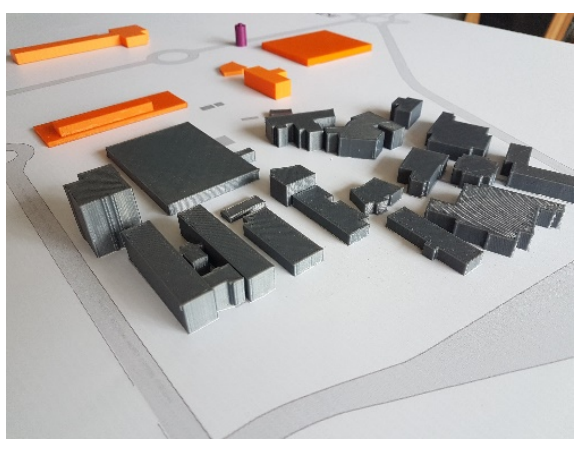

Figura 11: Setor cinza impresso. Fonte: Autores, 2019

\section{Resultados}

A fabricação da maquete-teste seguiu as indicações estabelecidas pela pesquisa, em que os modelos dos prédios impressos em 3D, em três cores diferentes (representadas por três setores), foram fixados em lona com proteção UV contendo a identificação de ruas, rótulas e edificações de menor porte, fixado em uma placa de compensado (Figura 12). Todo o conjunto foi apoiado em um suporte, também em compensado, para que o acesso às informações pudesse ser ergonomicamente confortável para a apreciação e consequente utilização. Para esta amostra (maquete-teste), foi criado um $Q R$ code, também em teste, que pudesse conduzir os entrevistados do local onde a maquete estaria posicionada até um ponto aleatório do campus que, no caso, o escolhido foi o departamento de Psicologia da universidade.

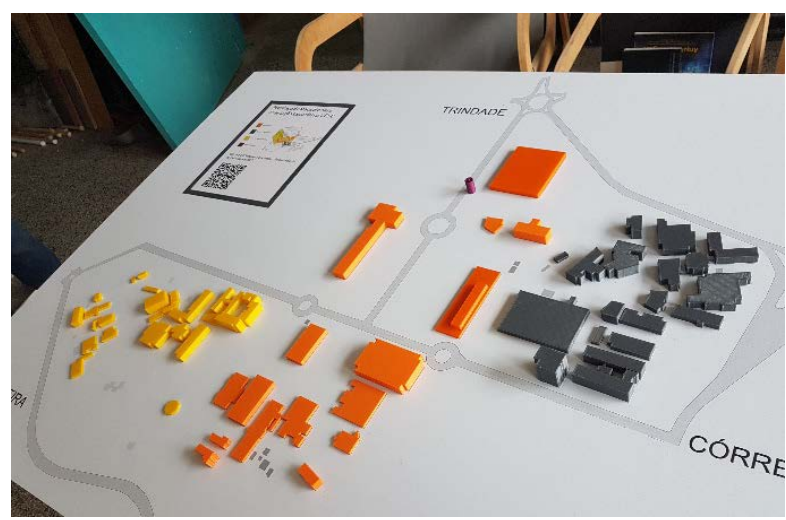

Figura 12: Maquete-teste. Fonte: Autores, 2019 
representação gráfica da planta do campus, $100 \%$ dos entrevistados conseguiram identificar os prédios dos centros de estudos ali demonstrados na maquete. As cores e setorização foram fundamentais nesta constatação.

A partir deste momento, a discussão, portanto, passava pelo desafio de como aprimorar os conceitos apresentados de acessibilidade, para pessoas com deficiência. No conceito de "design possibilities", esta faixa da sociedade merece respeito, inclusão e assistência quanto à facilidade de uso do produto sendo proposto. Em fase de implementação, a solução está sendo discutida no âmbito da deficiência visual, primeiramente, com a inserção das legendas em relevo, além de mecanismos que possibilitem a leitura dos melhores trajetos sem a necessidade de intervenção na própria estrutura da maquete.

Finalmente, ao serem perguntados a respeito de quais pontos de referência ou guias de localização poderiam complementar a maquete, uma resposta unânime apontou a necessidade de identificar, além da topografia do campus, como, por exemplo, o lago, córregos, pontos de referência externos ao campus e alguns marcos significativos como a caixa d'água e alguns cafés mais frequentados.

\section{Considerações finais}

O presente trabalho teve como objetivo entender e formular, com o uso das tecnologias de fabricação e prototipagem digitais, uma proposta de maquete que auxiliará na orientação espacial no campus Reitor João David Ferreira Lima da Universidade Federal de Santa Catarina. O momento para a realização da proposta não poderia ser mais oportuno, pois, desde 2017, o Departamento de Projetos de Arquitetura e Engenharia (DPAE) da UFSC desenvolve o projeto "Rotas Acessíveis", com o objetivo de garantir aos usuários do campus a acessibilidade aos espaços construídos da universidade. São relevantes as alterações que o projeto coloca na realidade do campus, com alterações estruturais nos caminhos entre edificações, nas edificações, pontos de ônibus e outros.

Dentro deste contexto, é necessário avaliar a proposição da maquete para auxiliar na orientação espacial no campus, seu local de inserção e sua contribuição prática. Nesta pesquisa, avaliou-se que existe uma percepção positiva sobre a inserção da maquete na Praça da Cidadania e suas adjacências, mas as adequações propostas pelo projeto "Rotas Acessíveis" demonstraram que a área de chegada na Biblioteca Universitária - pontos de ônibus e acessos para o campus a partir da Rua Delfino Conti - sofrerá alterações significativas e abrirá novas possibilidades para a colocação da maquete em um contexto mais integrado com a nova infraestrutura do campus.

Todo o material compilado por esta pesquisa, bem como o apoio dos laboratórios do PET Arquitetura e Urbanismo e do PRONTO3D, torna viável a execução da maquete com as tecnologias de fabricação e prototipagem digitais. A parceria com o DPAE e com a Secretaria de Obras, Manutenção e Ambiente da UFSC (SEOMA) é fundamental para a execução deste elemento 
